\title{
Effect of ground motions on nonlinear seismic behavior of corroded buried gas pipeline
}

\author{
S. Mohammad S. Kolbadi ${ }^{1}$, , Nemat Hassani ${ }^{2}$, S. Mahdi S. Kolbadi ${ }^{3}$, M. R. Shiravand ${ }^{2}$ \\ ${ }^{1}$ Department of Civil Engineering, Shahid Beheshti University of Technology, Tehran, Iran \\ ${ }^{2}$ Department of Civil Engineering, Shahid Beheshti University, Tehran, Iran \\ ${ }^{3}$ Department of Civil Engineering, K. N. Toosi University of Technology, Tehran, Iran
}

\section{Email address:}

mohamadkolbadi.pwut@gmail.com (S. M. S.Kolbadi), nemathasani@yahoo.com (Nemat Hassani), mahdi_kolbadi@sina.kntu.ac.ir (S. Mahdi S. Kolbadi), shiravand@aut.ac.ir (M. R. Shiravand)

\section{To cite this article:}

S. Mohammad S.Kolbadi, Nemat Hassani, S.Mahdi S.Kolbadi, M.R. Shiravand. Effect of Ground Motions on Nonlinear Seismic Behavior of Corroded Buried Gas Pipeline. American Journal of Civil Engineering.Special Issue: Structural Analysis Progresses: Designing, Analyzing and Testing. Vol. 3, No. 2-1, 2015, pp.9-13. doi: 10.11648/j.ajce.s.2015030201.12

\begin{abstract}
Recent earthquakes have damaged many lifeline structures. Buried gas pipelines are also no exceptions. Sometimes, theses pipes are subjected to a thinning of the wall thickness due to corrosion. Therefore, it is important to evaluate the strength of the pipes undergoing local wall thinning to maintain the integrity of the piping systems. The main purpose of this study is to understand failure aspects of buried pipeline caused by earthquake and degradation of metal due to corrosion through FEM. In dynamic analysis, corroded pipeline approaches to critical criteria (reaching the yield stress) in much less time. In this case, if the corroded pipe thickness be half, the yielding angle is reduced to a quarter.
\end{abstract}

Keywords: Buried Pipeline, Corrosion, Fault, Landslide, Yielding Pressure, Seismic Response

\section{Introduction}

The damage or disruption of buried pipelines due to earthquakes may severely affect civil lifeline structures since it may cause fires, economic losses, and disable of lifeline networks. Furthermore, if they are exposed to corrosion, material strength is severely reduced. As a matter of fact the damage will be propagated.

Corrosion is one of the most critical degrading mechanisms of structural strength. Moreover, corrosion of most metals is often an inevitable process. When localized, pit or uniform corrosion occurs, strength reduction can be difficult to establish because of the complicated effects of uneven surfaces and uneven material properties on the stress fields and failure modes of the structure. In order to accurately estimate pipeline structure life, it is important to understand and evaluate corrosion effects on overall ductile fracture, bending capacity and the corresponding local strength [1].

Based on the severity and intensity of corrosion, the material loss can be converted into an overall reduction in plate thickness and a corresponding decrease in the strength of the structure. Although the concept of an overall thickness reduction is simple to apply, it may be inaccurate as some important local phenomena may be overlooked [1].

Gas pipelines, are types of structures that are highly susceptible to corrosion. As the geometry features of such inand out-of-water structures, corrosion effects on shell structures are of special interest in studying the corrosion effects on pipelines. For pipelines, internal and external pressures, and bending moments are regarded as the most important loading conditions. Pipelines sustain huge external pressures from water and soil, internal pressures from transmitted oil or gas and bending moments due to thermal expansion and curved lay-out. When these pipes are corroded from either external or internal (or both), burst and bending capacities are decreased; thus, the structural integrity is significantly affected. Therefore, guidelines are needed for the estimation and calculation of these reductions [1].

\section{Pipe Specimen}

The material of pipe specimens are carbon steel pipes for high pressure service, called 'STS370', which are commonly used in piping systems. The carbon steel of STS370 is similar to that of ASME A333 Gr.6[3].The inside pressure of those 
pipes are 250 Psi[2] andelasto-plastic behavior of the steel material is defined as follows (Figure 1):

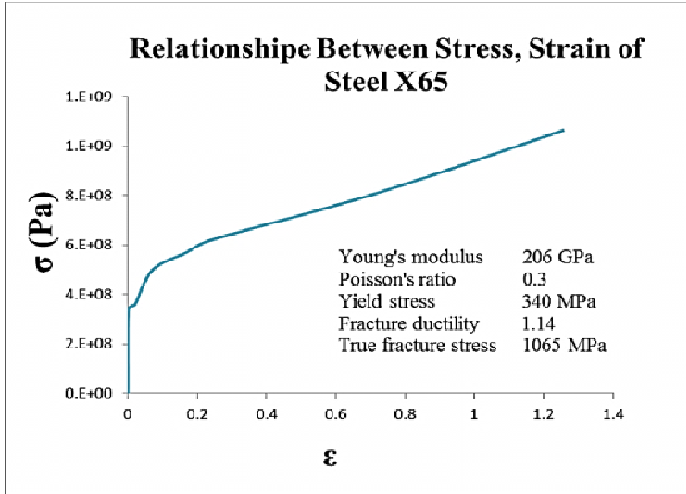

Figure 1. Stress-strain curve for FE analysis [3].
Since the chemical process ofcorrosion caused a huge reduction of the stiffness and the fracture behaviors of pipes with wall thinning on the outside of the pipes are almost identical to those of pipes with wall thinning on the insidesurface [4], thus; corrosion effect is expressed by local wall thinning roundly.

The corroded pipe geometric can be seen in the figure 2 .

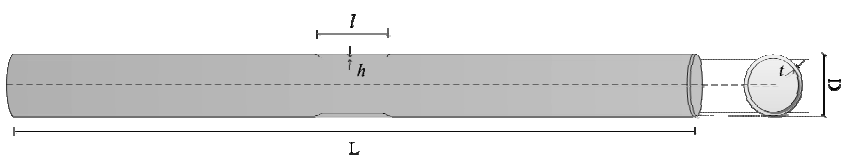

Figure 2. Shape and dimensions of a pipe specimen with circumferentially local wall thinning

Table 1. Geometric dimension of the pipe[2,3]

\begin{tabular}{|c|c|c|c|c|c|}
\hline$\alpha=\mathbf{h} / \mathbf{t}$ & $l$ & $\boldsymbol{h}$ & $t$ & $D$ & $L$ \\
\hline Corrosion ratio & Length of corrosion & Thickness of corroded pipe & Thickness of sound pipe & External diameter & Pipe's length \\
\hline $0 \sim 1$ & $L$ & Variable & $14.3 \mathrm{~mm}$ & $1 \mathrm{~m}$ & $30 \mathrm{~m}$ \\
\hline
\end{tabular}

The magnitude of $\alpha$ varied from 0 to 1 . If $\alpha$ be closed to 1 , it means the pipe is sound and if atended to 0 , it demonstrates there is so corrosion on pipe's wall.

\section{Properties of Buried Pipeline}

\subsection{Geometric Properties}

The model geometry, due to the impact of soil-structure interaction is intended as figure 3 .

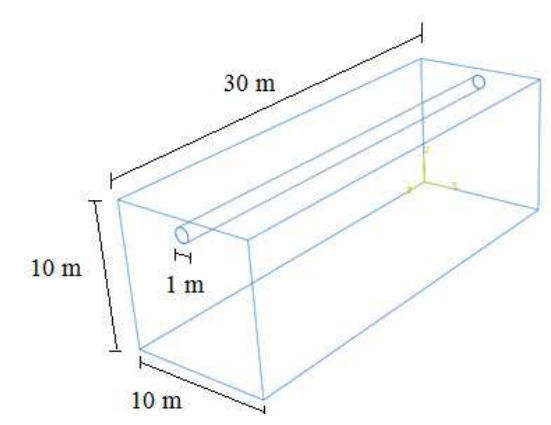

Figure 3. Geometric properties of buried pipeline

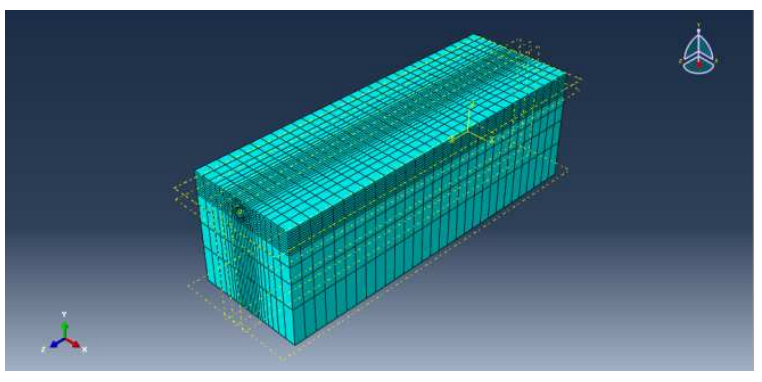

Figure 4. Buried pipeline meshed-3D plane

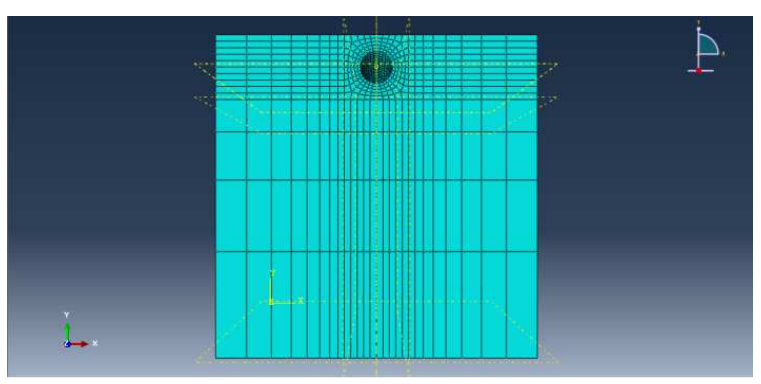

Figure 5. Buried pipeline meshed-2D plane

\subsection{Soil Properties}

Table 2. Soil properties[5]

\begin{tabular}{lll}
\hline Cap Model & & \\
\hline Elastic Modulus & $E$ & $5 \mathrm{MPa}$ \\
Poison's Ratio & $v$ & 0.2 \\
Unsaturated Density & $\rho$ & $1923 \mathrm{Kg} / \mathrm{m}^{3}$ \\
\multirow{2}{*}{ Cohesion } & $C^{\prime}$ & $5.1 \mathrm{KPa}$ \\
& $d$ & $30 \mathrm{KPa}$ \\
Internal Friction Angel & $\phi^{\prime}$ & $30 \mathrm{Degree}$ \\
& $\beta$ & 50.2 Degree \\
\hline
\end{tabular}




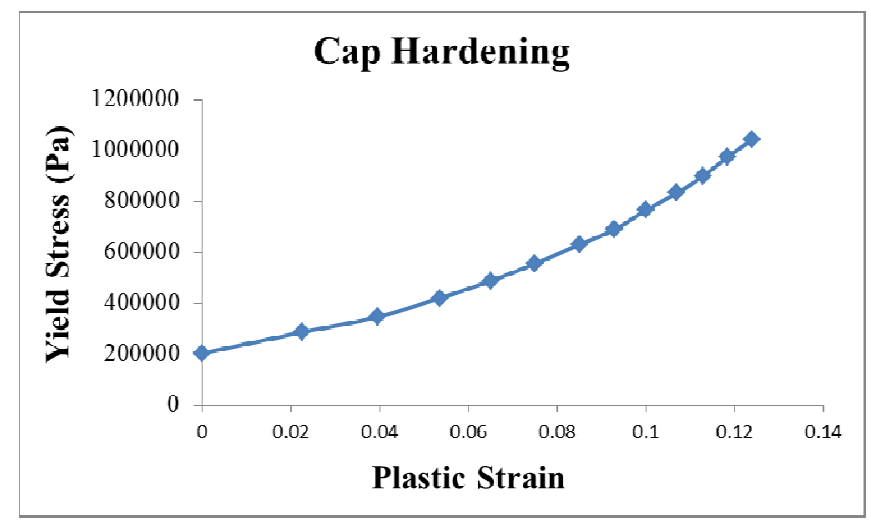

Figure 6. Cap hardening curve of cap model[5].

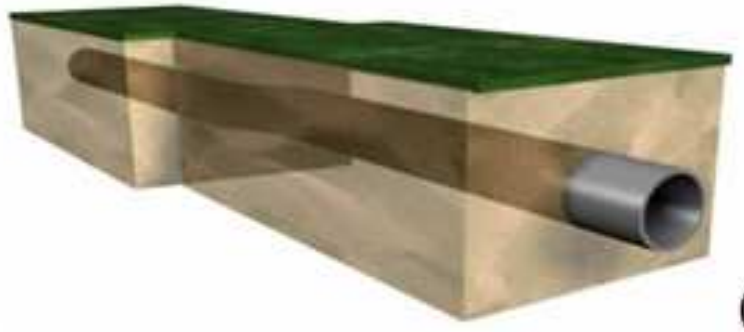

(a)

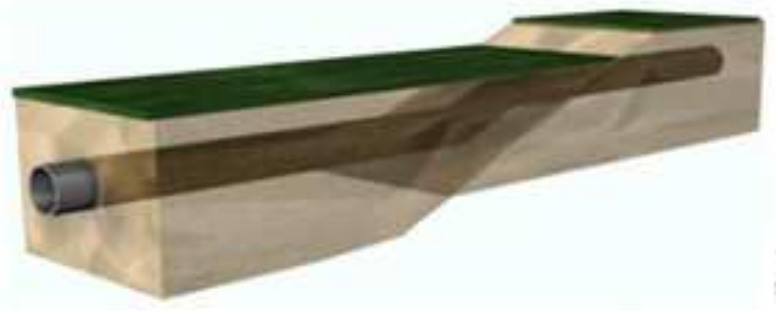

(c)

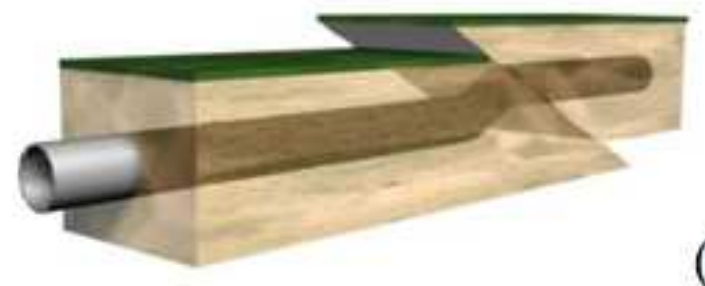

(d)

\section{Dynamic Analysis}

The behavior of buried pipelines is depended to the ground motion closely in both lateral and longitudinal directions. Therefore, examining the relative displacements between buried pipelines and ground are suitable for estimating failure aspects of buried pipelines caused by earthquake because the behavior of buried pipelines is mostly governed by relative ground movement from earthquake [6].

Two major influences of the earthquake on buried pipes is:1. drift between soil and pipe in longitudinal direction (Figure7, 8);2. bending pipe caused by earth movement (Figure9). Therefore both factors may impact to the stress caused by corrosion.

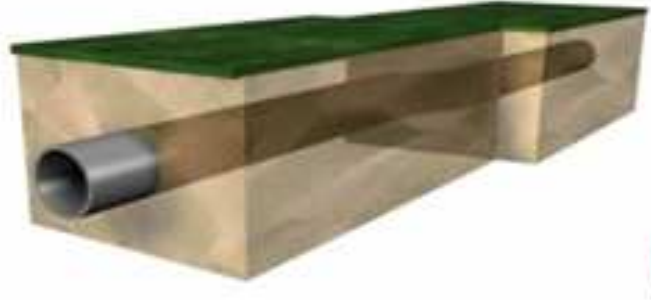

(b)

Figure 7. Type of buried pipeline-fault crossing (a) Pipeline subjected to left lateral fault movement, (b) Pipeline subjected to right lateral fault movement, (c) Pipeline subjected to normal dip slip fault movement and (d) Pipeline subjected to reverse dip slip movement

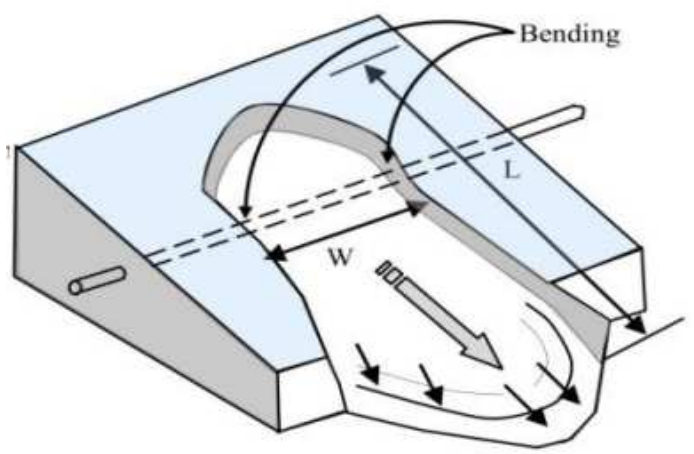

Figure 8. Transverse Pipe-PGD crossing

\subsection{Pipe's Bending}

At first the impact of ground motion that causes the bending of pipe is studied. This phenomenon happens where, fault and pipe are crossover. In this regard, a distinct drift

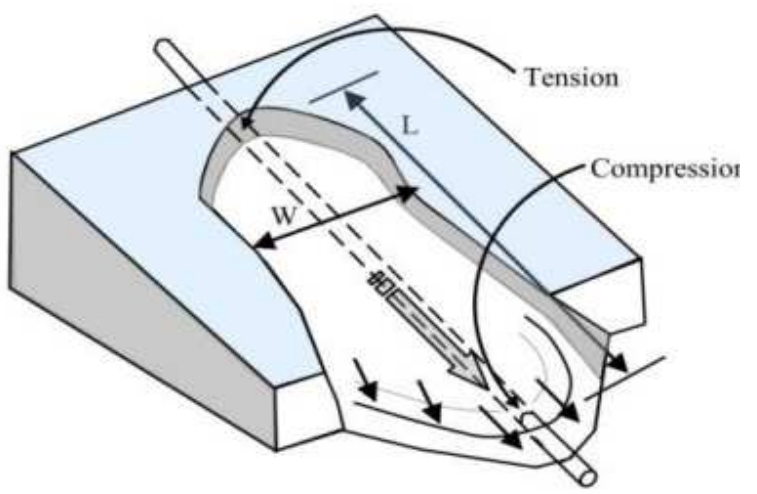

Figure 9. Longitudinal and Pipe-PGD crossing

were applied to the soil in the perpendicular of pipe sdirectionfor describe to the corroded pipe crossing fault and it was compared with sound pipe. Ground motion had 10 seconds duration and $10 \mathrm{~cm}$ drift. 


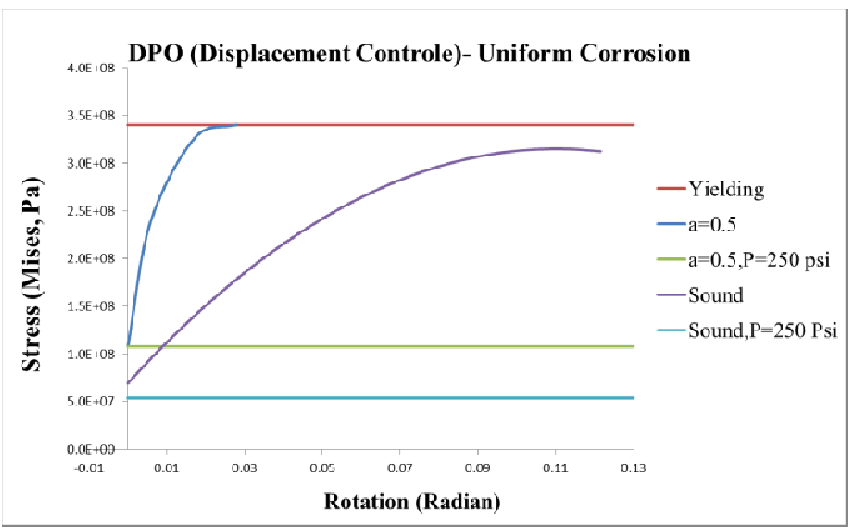

Figure 10. The effect of bending caused movement of fault on the corroded pipe

As it can be observed the curves are performed by movement control. The corroded pipes with a $\alpha=0.5$ was chosen. Corroded pipe reached to the yielding level at lower rotation angel compared to the sound pipe. The yielding rotation angle of sound pipe is 4 times more than of corroded pipe approximately.

\subsection{Pipes Tensile}

If the ground be parallel to the pipe's direction, the tensile stresses will be create. Thus to understand the influence of the drift between the pipe and the soil, it is important to evaluate this phenomenon that occur in landslide usually. In this case, the effect of soil-structure interaction is very important. Whatever the involvement of soil and pipe be too much, tensile stresses are more in pipe. So,when the pipe will be corrode,the pipe would be much weaker.

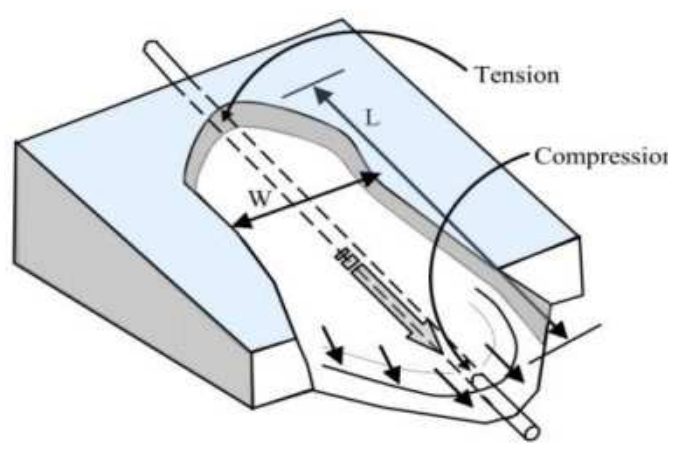

Figure 11. Longitudinal and Pipe-PGD crossing

It is possible to divide soils into two groups, which are sandy soils and cohesive soils. Sandy soil is often called frictional soil or drained soil and cohesive soil is normally classified as undrained soil. These two groups of soils have different characteristics and can cause different failure modes for buried structures.

The interaction effects were applied by contact element that it is contain two types of transmissionforces:

- Normal

- Tangential

The tangential behavior with considering the friction coefficient $(F)$ between the pipe and soil was definedusing Columbus theory [5] that provides the equivalent stiffness of the soil and the pipe. For cohesive soils and coarse-grained soil, $F=1$ and $F=0.1$ was considered respectively and the results were compared to sound and corroded pipes.

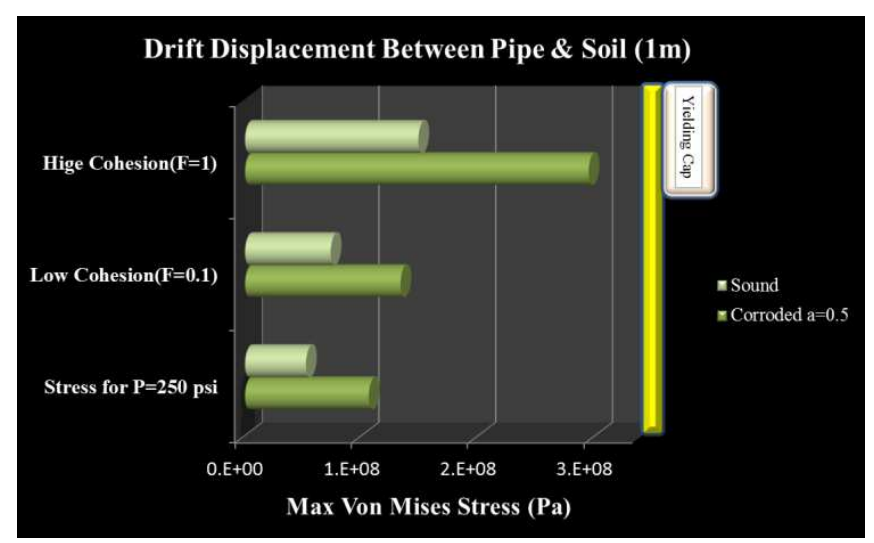

Figure 12. Effect of the drift displacement between pipe and soil on the corroded pipe

It can be seen that the stress values incorrodedpipe is more than of the sound. With increasing the friction between the soil and the pipe, maximum stress increases.

\section{Conclusions and Discussions}

Thestudieswere performed on the effect ofcorrosionontheseismicresponses of pipes causedby the ground motions. Since the buried pipes confine with surrounding soil, the dynamicresponse of pipeaffected by the ground movements. Themass of thepipeisvery small compared to thesurroundingsoil, so equal stiffness between soil and pipe be considerable. Thus; it seems reasonable to use displacement control instead of acceleration-time in historical analysis.

In the first study, corrodedpipelineapproaches to critical criteria(reaching the yield stress) in muchlesstime. In thiscase, ifthe corrodedpipethickness be half, the yielding angle is reducedto a quarter.

In the other case, formodeling the landslidephenomena, a falsedrift(about $100 \mathrm{~cm}$ ) was apply betweenthe pipeand soil. During thisinterval, the tension stresscontourshowedvarying amountsthat were highly dependent on the surrounding soil type.Therefore, forbetter comparison, the mean of the valueswasused. This comparison was madebetween thesound pipeand thecorroded pipe with $\alpha=0.5$. The important parameterinthisphenomena is the equivalentstiffnessbetween thepipe and thesoil.

To express the equivalent stiffness, the simple and practical theory of Columbuswas used. The result shows, whateverthe equivalent stiffness between the pipe and the soil be less, the tension will less in both sound and corroded pipes. Average stresses in corroded pipe is 2 times the sound pipein all of the modes (Without motion, movement of cohesive soil, and movement of granular soil) approximately. 
The most critical state occurs when the soil is cohesive. In this state, the corroded pipe stress values are very close to the yielding stress. Therefore, it is better to use, coarse and granular soil around the pipe when the pipes are buried.

\section{References}

[1] Weiwei Yu. Corrosion Effects on the Ductile Fracture, Strength and Reliability of Membranes, Plates and Shells, Dissertation, 2009, 1.

[2] A. Aghasi. Investigating the performance of the pressure gas pipe on explosions, PWUT University, 2012, 46.
[3] M. Ono, K. Woo Nam, K. Takahashi, K. Ando. Effect of Local Wall Thinning on Fracture Behavior of Straight Pipe, Nuclear Engineering and Design, 2002, 1

[4] K. Miyazaki, S. Kanno, M. Ishiwata, K. Hasegawa, S. H. Ahn, K. Ando, Nuclear Engineering and Design, 1999, 191

[5] A.S. Daryan, H. Bahrampoor, H. Arabzade. Complete Manual of ABAQUS. Angeizeh Publishing Co- ISBN 978-964-751744-7, 2011

[6] LEON, R. L. \& WANG, M. (1978) Performance of underground pipelines in earthquake. IN DIVISION, A. G. E. (Ed.) Earthquake engineering and soil dynamics. New York, American Society of Civil Engineers. 